\title{
Çocuk Edebiyatında Sanata Yolculuk: Müze Eğitimi
}

\author{
Dr. Öğr. Üyesi Nuran BAŞOĞLU* \\ Zonguldak Bülent Ecevit Üniversitesi, Ereğli Eğitim Fakültesi, Türkçe Eğitimi Bölümü, \\ Zonguldak / Türkiye, nuranbasoglu@hotmail.com, ORCID: 0000-0001-7034-2629
}

\section{$\ddot{O} z$}

Son y1llarda önemi ve gerekliliği anlaşılan müze eğitiminin çocuklara ve gençlere sağlayacağı birçok yarardan bahsetmek mümkündür. Müze eğitimi bireye öncelikle kendi kültürünü ve farklı milletlerin kültürlerini tanıma imkânı yani kültürel farkındalık kazanma şansı sunar. Estetik gelişimi ve değer eğitimini de destekleyecek olan müzelerin çocuk yaşlarda keşfedilmesi ve sanata olan ilginin bu yolla artırılması sağlanabilir. Bu amaçla çalışmada tarama yöntemi ile çocuk edebiyatında müze eğitimini konu edindiği belirlenen on üç kitap döküman incelemesi yapılarak incelenmiş ve elde edilen veriler betimsel analiz ile sunulmuştur. Kitaplar; müze gezisi odaklı yazılanlar, kendi müzesini oluşturma fikriyle yazılanlar, etkinlik ve uygulama odaklı yazılanlar olmak üzere üç başlıkta sınıflandırılmıştır. Kitapların; bir müze gezisinde uyulması gereken kuralları aktardığı, dünyadaki ve ülkemizdeki müzeleri ve sanat eserlerini tanıtmayı başardığı görülmüştür. Ayrıca kitaplarda müzelerin eğlenceli ve hayal gücünü harekete geçiren mekânlar olduğu vurgusu yapılarak olumlayıcı bir bakış açısı oluşturulmuştur. Sonuç olarak çocuklar için yazılan kitapların öğretmenler ve ebeveynler tarafından müze eğitiminde kullanılabilecek rehber niteliğinde eserler olduğu belirlenmiştir.

Anahtar Kelimeler: Çocuk edebiyatı; Müze eğitimi; Sanat ve çocuk; Çocuk müzesi; Çocuk kitapları. 


\title{
Journey to Art in Children's Literature: \\ Museum Education
}

\begin{abstract}
It is possible to mention about many benefits that museum education whose importance and necessity has been understood in recent years will provide children and young people. Museum education gives an individual the opportunity to get to know his own culture primarily and then the cultures of different nations, in other words, it provides cultural awareness. It is possible to discover museums which will also support aesthetic development and value education and to enhance interest in art by this way at the age of childhood. For this purpose, thirteen books that were determined to be about museum education in children's literature by using survey method. These books were analyzed by means of document analysis and the data obtained were presented through descriptive analysis. The books were categorized under three headings: those written with a focus on museum tour, those written with the idea of creating their own museum, and the ones written with the focus on activity and practice. It was seen that the books explained the rules to be followed during a museum tour and they succeeded in promoting the museums and artworks in the world and in our country. In addition, an affirmative perspective was created by emphasizing in the books that museums are enjoyable places and they stimulate imagination. As a result, it was decided that the books written for children are guidance works that can be used by teachers and parents in museum education.

Keywords: Children's literature; Museum education; Art and children; Children's museum, Children's books.
\end{abstract}

\section{Extended Summary}

\section{Purpose}

It is possible to mention about many benefits that museum education whose importance and necessity has been understood in recent years will provide children and young people. Museum education gives an individual the opportunity to get to know his own culture primarily and then the cultures of different nations, in other words, it provides cultural awareness. Museums will also enhance aesthetic development and value education, and they can be discovered in childhood. By this way, an interest in art can be increased. For this purpose, children's books written for museum education were determined by means of survey method. 


\section{Method}

In the survey model which is one of the qualitative research methods and aims to present the situation as it is, the purpose is to define the events, individuals, or objects of the research in their own conditions and as they exist (Karasar, 2012). Thirteen books on museum education were identified as a result of the literary review.

Data were obtained from the books by document analysis. Document analysis covers the analysis of written materials containing information about the facts and cases that are aimed to be studied (Yıldırım and Şimşek, 2008). The obtained data were presented with descriptive analysis. The purpose of this type of analysis is to present the obtained findings to the reader in an edited and interpreted form (Yıldırım and Şimşek, 2008).

\section{Results}

The books analyzed are classified under three headings according to how they handle museum concept: those written with a museum trip focus, those written with the idea of creating your own museum, the ones written with activity and practice focus. While seven of the thirteen books were designed on museum trip, three of them were written to highlight the idea of creating their own museums in children and the rest of the books were prepared with activities and practical studies.

Most of the books analyzed are fictionalized on a museum visit. While these visits, which are desirable in museum education can be accompanied by a teacher or a parent, they can be made with peers or individually based on the age group. Although the museum tour is accompanied by elders such as teachers, mothers, aunts, and grandmothers in the books analyzed, the trip is mostly completed with friends or individually in fiction. This will be beneficial in creating a museum culture and awareness in children. They also convey the rules to be followed in museums during these visits. In the books analyzed, it is seen that museums are highlighted as educational environments suitable for learning while having fun. The idea that museums are fun places and they develop imagination is included in all works.

The common idea in all the three books which were written for children to gain the idea of creating their own museums is that children can acquire the concept of museology by making and experiencing activities such as either collecting valuable or interesting products or creating it themselves. Thus, museums are likely to be more meaningful and interesting places for children. 
Although there is no fictional text in the activity and practice-oriented books, it is revealed that museum education will become fun with its applicability and activities. By providing an environment of discovery and adventure to children, it was aimed to increase an interest in museums and artworks.

\section{Conclusion}

Museum education in children's literature has started to gain a remarkable identity by means of children's books. The books analyzed in the study possess the necessary features in terms of museum education. As a result of the analysis, the books were classified under three headings: those written with a museum trip focus, those written with the idea of creating Your Own Museum and the ones written with an Activity and Practice focus. While most of the books analyzed in this study succeeded in conveying the rules to be followed in a museum tour in fiction, they also highlight the idea that museums are fun places and they stimulate imagination. Including child heroes suitable for identification in the books, giving children the idea of establishing their own museums based on their interests, and preparing joyful activities designed with activities will support museum education. The fact that the books include artworks and museums throughout the world and our country is a positive attitude in creating a perspective towards different cultures and civilizations. The idea that museums are not boring places and art is in fact a powerful tool in conveying human emotions is handled in the children's books analyzed in this study. The prejudices created by the feeling of incomprehensibility towards museums and artworks in children will be broken through these books. While including visuals and information about artworks in the books and introducing the painters provide aesthetic development, giving information in order to discover and protect the works of our culture also serves for values education. It was observed that the books that enable reading and practice in company with teachers and parents carry the suitable qualification for museum education.

\section{Müze Eğitimi}

\section{Giriş}

Müze; sanat ve bilim eserlerinin veya sanat ve bilime yarayan nesnelerin saklandığı, halka gösterilmek için sergilendiği yer ve yapı olarak tanımlanır (Türk Dil Kurumu, 2020). Müzeler doğal, tarihî, sanatsal, bilimsel değerlerle ilgili objelerin saklandığg, korunduğu, incelendiği ve sergilendiği kurumlardır. Sanat müzeleri, arborotrumlar, botanik bahçeleri, tarihi evler, doğa 
tarihi müzeleri, tarih müzeleri, çocuk müzeleri, teknoloji merkezleri dünyanın dört bir yanında ziyaretçilerin sürekli gezdiği yerlerdir (Kuruoğlu-Maccarı, 2002).

Sanat, tarih ya da bilim kitaplarında yer alan bilgilerin, nesneler arac1lığıyla canlandırıldığı mekânlar hâline dönüşen müzeler ve müzelerin zamana, mekâna, değerlere göre değişen işlevsel boyutu her dönemde sorgulanmıştır (Ilıcak-Aydınalp, 2019). Tarihsel geçmiş hakkında aydınlatıcı bilgiler veren müzelerin farklı dönemlerde öncelik sırası değişen, toplama, koruma, sergileme, araştırma ve eğitim gibi beş çeşit sorumluluk alanı vardır. Bilişim alanında yaşanan gelişmelerle birlikte müzelerin sosyal ve eğitimsel işlevleri diğer sorumluluk alanlarının önüne geçmiştir. Toplumların yaşamış oldukları değişimlerle birlikte müzeler, yeni bilginin ve ortaya konulan birikimlerin inşacısı durumuna gelmiştir. Birçok müze, koleksiyon biçimlerinde, uygulamış oldukları yöntemlerde, izleyici kitlesinin özelliklerinde ve yönetim ile organizasyon boyutunda eğitimi öncelikli hâle getirecek yapılanmalara gitmiştir (Göğebakan, 2016).

19. yüzyıldan günümüze kadar müzeler, yaygın eğitim kurumları olma yolunda büyük ilerleme kaydetmişlerdir. Müze eğitimi, çağdaş eğitim anlayışının bir parçası olarak farklı deneyimler yoluyla hayat boyu kazanılan davranış değişikliklerini yönlendirmede örgün eğitime büyük oranda katkı sağlayan bir duruma gelmiştir (Özmen, 2018). Günümüzde eğitim, müzelerin temel işlevleri arasında kabul edilmekte; müze eğitimi insanların var olan bilgi, yetenek ve kişisel ilgilerine göre müze koleksiyonlarından deneyim kazanmalarını, kendi anlamlarını çıkarmalarını sağlama ve hayat boyu eğitimlerine katkıda bulunma süreci anlamını taşımaktadır (Tezcan-Akahmet ve Ödekan, 2006). Müzeler; geçmişe ait nesneleri toplama, koruma, belgeleme ve sergileme görevini üstlenen kurumlar olmanın yanı sıra, toplumun eğitim düzeyini artırma, estetik duyarlılığını geliştirme, bugün, geçmiş ve gelecekte yaşananları/yaşanacakları açıklama, yorumlama, karşılaştırma, toplumsal değişimleri yönlendirme ve kişilerin eğlenerek, hoş vakit geçirerek zamanını değerlendirme amaçlarını da yerine getirme sorumluluğu olan kurumlardır (Çakır-İlhan ve ark., 2019).

Ülkemizde müzelerden eğitim amacıyla yararlanmanın ilk örneği 1868 yılında Galatasaray Mekteb-i Sultani'de kurulan okul müzesi ile görülür. Daha sonra 1930'da Bursa'da bir ilkokul ve bir lisede birer okul müzesi açılmış ve 1958 'de öğretmenler için müze el kitabı çıkarılmıştır (İMEM, 2011). 
Müze eğitiminin eğitim öğretim programlarında yer alması ise yapılandırmac1 yaklaşımın benimsendiği 2006 yılında başlar. Talim ve Terbiye Kurulu kararıyla 2005-2006 eğitim-öğretim yılından itibaren ilköğretim 1-8. sinıfların Türkçe, matematik, sosyal bilgiler, hayat bilgisi ile fen ve teknoloji dersi öğretim programlarında müze ile eğitime yer verilmiştir. İlköğretim görsel sanatlar ders programının öğrenme alanlarından birini müze bilinci, sanat etkinlikleri ders programının öğrenme alanlarından birini ise müze kültürü oluşturmuştur. Öğretim programları içinde müze ile eğitimin hedeflerine şöyle yer verilir: Kültürel varlıkları, tarihî eserleri anlama, koruma, değerlendirme ve yorumlama becerisi ile zaman ve mekân algılama becerisi gelişmiş; kültürel ve kültürler arası hoşgörü becerisi kazanmış, kendilerini çevreleyen dünyaya karşı görsel farkındalıkları olan; geçmiş, bugün ve gelecek arasında bağ kurabilen, arşivleme bilincine sahip, toplumsallaşmış bireyler yetiştirmek (Millî Eğitim Bakanlığı, 2008). Öğretim programlarında müze eğitimine yer verilerek eski eserlerin, anıtların tarihî birer belge olma yönlerine dikkat çekmek ve bu kültürel miras ögelerinin kaybolmasını, zarar görmesini, yabancıların eline geçmesini engelleme konusunda millî bir bilinç oluşturmak amaçlanmaktadır. Şar ve Sağkol'a (2013) göre anlatılan derslerin somutlaştırılmasında etkin olarak kullanılabilecek, yapılandırmacı eğitimin hedeflediği etkin ve aktif öğrenmeyi gerçekleştireceği düşünülen müze ile ilgili aktiviteler, bilinçli ve müze eğitimi konusunda bilgili ve eğitimli öğretmenler tarafından uygulandığı takdirde istenilen sonuçlara ulaşılabilir. Bu bağlamda benzer yönelim eğitim fakültelerinde görülmüş, öğretmen adaylarını bu alanda yetiştirmek amacıyla birçok lisans programında müze eğitimi seçmeli dersi okutulmaya başlanmıştır. Ayrıca Millı̂ Eğitim Bakanlığı Öğretmen Yetiştirme ve Geliştirme Genel Müdürlüğü tarafından "Müze Eğitimi Kitabı" hazırlanmıştır. Yine öğretmenlerin, müzeleri eğitim ortamı olarak kullanmaları, çocukların sınıf içi öğrenmelerini daha gerçekçi öğrenme ortamlarına taşıyarak farkındalık, bilinç ve beceriye ilişkin kazanımlarını birleştirmek için 2019 yılının mayıs ayında Öğretmen Yetiştirme ve Geliştirme Genel Müdürlügünce Müze Eğitimi Sertifika Programı başlatılmış ve iki yıl içerisinde 15 bin öğretmenin müze eğitimi alması hedeflenmiştir (Millî Eğitim Bakanlığı, 2019).

Günümüzde müze yalnızca nesne koleksiyonlarından ibaret değildir. Müze bugün, ziyaretçileriyle iletişime geçen, farklı yaş gruplarına eğitim veren, bireysel gelişime katkı sağlayan, toplumsal barışı ve kalkınmayı destekleyen dinamik ve sıra dışı bir kurum özelliği kazanmıştır (Karadeniz ve Okvuran, 2014). Öğrencilerle yapılan bir müze ziyareti çocuklara, toplumsal 
ilişkiler, kültürlerini tanıma ve bir araya gelerek sosyalleşme imkânı sunacaktır. Okuldaki öğrenme ortamında kendini gösteremeyen öğrenciler böyle ortamlarda yetenek ve ilgilerinin farkına varabilir ve kendini ifade edebilme imkânına sahip olur. Bilgi sürekli aynı ortamda durağan şekilde verilmediği için çocuk çok yönlü bir öğrenme ortamında kendini geliştirecek ve daha çok verim alınacaktır (Bulut ve Atilla, 2017). Müzelerin eğitim ortamına dönüştüğü günümüz şartlarında çocukların müzelere olan ilgisini artırmak, müzeleri çocuklar için bir keşif sahasına dönüştürmek gereklidir. Bu amaçla müze ve çocuk ilişkisine eğilmek yerinde olacaktır.

\section{Müze ve Çocuk}

Sanat eğitiminin amaçlarının başında "sanatın evrensel dilini kullanabilme" gelir. İnsanın, sanatsal düşünce yoluyla kendini dışa vurması büyük önem taşır. Bireyin kendi öznel evrenini tanıması ancak kendi dışındaki nesnel evreni tanımasıyla olasıdır. Bu yolla kazanılan deneyimler, kişinin kendini anlatmada önemli bir araç olabilir ve kişiyi özgünleştirebilir. Özgün anlatım çabas1, özgün düşünmenin temelini oluşturan eleştirel düşünmeyi ve sentez-yorum yapmayı birlikte getirmektedir (Alakuş, 2005). Çocuğun duygu dünyas1nın gelişmesine yardımcı olacak en uygun koşullar, sanat dersleriyle sağlanabilir. Çocuk ve genç, sanat eğitimiyle bakmak yerine görmeyi, duymak yerine işitmeyi, dokunduğunu hissetmeyi kısacası farkında olmayı, algılamayı öğrenecektir. Çünkü sanat eğitimi bir duyarlılık eğitimidir (Y1lmaz, 2010).

Bireylerin çocukluktan itibaren başladıkları sanat eğitimi süreci aktif olarak dâhil oldukları müze eğitimi süreci sayesinde daha anlamlı bir hâl alacaktır. Eleştirel düşünen, belli bir estetik beğeniye sahip olan, yaratıcı fikirleri ve geniş bir hayal gücüne sahip olan bireyler, bu özelliklerini tüm hayatına yansıtarak sanat eğitimini hayatlarının her evresinde hissedeceklerdir (Bulut ve Atilla, 2017). Müze çocuk eğitiminde, çocuğun kendisi vardır ve temel esas da çocuğu geçmişle konuşturmaktır. Bu çalışma 6-10 yaş çocukları için çok önemlidir (Abac1, 1996). İyi bir planlama (müze öncesi, müzede ve müze sonras1), uygun düzenlemeler, müze kurallarına uyma ve çocuklara, doğru yaklaşımlarla müze deneyimlerinin; çocukların araştırma, keşfetme, merak, inisiyatif kullanma, yaratıcılık, önceki bilgilerini kullanma, sorgulama, karşılaştırma, destekleme, eleştirel düşünme, akıl yürütme gibi zihinsel süreçleri ile estetik zevklerinin gelişmesinde ve kendilerini ifade etmelerinde firsatlar sunarak onların kültürel eserlere sahip çıkma, koruma, saklama ve müze gezme 
bilinci edinmelerine de katk1 sağlayacağı düşünülmektedir (Ünal ve Pınar, 2017).

Batı'da ister bilim ister teknoloji olsun ister tarih ya da sanat olsun hemen hemen her müze, yetişkinler için kurulan müzelerde çocuklara bir yer ayırmaktansa, doğrudan çocuk müzeleri açmayı yeğlemektedir. Çevreyle ve kendi tarihleriyle ilişki kurmanın çocukluktan itibaren olması gerektiği anlayışı bu müzelerin temel politikasını oluşturmaktadır (Abacı, 1996). Çocuk müzeleri yalnızca çocuklar için tasarlanmış, çocukların eğitimini ve gelişim alanlarını bütünsel olarak desteklemeye özen gösteren belli bir koleksiyona sahip olmak zorunda olmayan müzelerdir. Çocuk müzelerinin ortak amacı yaratıcı oyun ve dokunarak öğrenme etkinlikleri yoluyla eğitimdir (Abacı, 2005). 19. yüzyıldan beri Amerika ve Avrupa'da kurulmaya başlayan çocuk müzelerinde, müze eğitimi yapılmaya başlanmıştır (Kuruoğlu-Maccarı, 2002). Batı'daki müzecilik anlayışında müze, okulun vazgeçilmez bir tamamlayıcısıdır ve çocuklar yarının ziyaretçileridir.

Çocuklara yönelik olarak müze eğitimi bağlamında ülkemizde yapılan çalışmalara bakıldığında güzel adımlar atıldığı görülür. Kültür ve Turizm Bakanlığınca 2009'da başlatılan “Çocuk Dostu Müze Projesi” ile gençlerin müze bilincinin artırılmasını hedeflenmiş ve 2011'de UNICEF ile Müze Eğitim Modülü oluşturularak çocuklara yönelik eğitim verilmeye devam edilmiştir. Projenin başlangıç tarihinden bu yana çocukların müzelere karşı ilgilerinin büyük oranda arttığ tespit edilmiştir (Timetürk, 2011). Müze ziyaretlerinin çocuklar için keyif verici ve aynı zamanda daha anlamlı olmasını amaçlayan müzeler, hafta sonları çocuklar için bol eğlenceli etkinlikler, eğitimler ve atölye çalışmaları oluşturmuştur. Sakıp Sabancı Müzesi 2014 yılından itibaren çocuklar için hazırladığı kitapları yazılı ve sesli seçenekleri ile internet adresinde paylaşarak çocukların müze kültürü hakkında bilgi edinmelerine katkı sağlamaktadır. 2016 yılında uluslararası çapta pek çok örneğine rastladığımız resimli çocuk kitapları müzelerinin bir benzeri, Ege Üniversitesi'nin destekleriyle İzmir'de çocuk kitapları resimleyen 27 sanatçının orijinal eserlerine yer verilerek kurulmuştur. 2017 yılında şair-yazar Sunay Akın'ın küratörlüğünde Kartal Belediyesi Masal Müzesi kurulmuştur. 2019'da ziyarete açılan Cin Ali Müzesi'nde okul öncesi yaştan başlayarak örgün eğitimin her basamağına uygun müze içi eğitimler planlanmıştır. 


\section{Yöntem}

\section{Araştırma Modeli}

Son y1llarda önemi ve gerekliliği anlaşılan müze eğitiminin çocuklara ve gençlere sağlayacağı birçok yarardan bahsetmek mümkündür. Müze eğitimi bireye öncelikle kendi kültürünü ve farklı milletlerin kültürlerini tanıma imkânı yani kültürel farkındalık kazanma şansı sunar. Estetik gelişimi ve değer eğitimini de destekleyecek olan müzelerin çocuk yaşlarda keşfedilmesi ve sanata olan ilginin bu yolla artırılması sağlanabilir. Bu amaçla çalışmada müze eğitimine yönelik yazılan çocuk kitapları tarama yöntemi ile belirlenmiştir. Nitel araştırma yöntemlerinden biri olan ve var olan durumu olduğu şekliyle ortaya koymanın amaçlandığı tarama modelinde araştırmaya konu olan olay, birey ya da nesne kendi koşulları içinde ve olduğu gibi tanımlanmaya çalışılır (Karasar, 2012).

\section{Çalışma Grubu}

Yapılan alanyazın taraması sonucunda müze eğitimi konusunu işleyen ve bu çalışmada incelenecek olan on üç kitap tespit edilmiştir. İncelenen eserlere dair bilgilere Tablo 1'de yer verilmiştir.

Tablo 1. İncelenen Eseler

\begin{tabular}{lll}
\hline Eser Adı & Yazar Adı & Yayınevi \\
\hline Müzede Bir Gün & Ezgi Berk & Final Kültür Sanat Yayınları \\
\hline Konya'da İz Peşinde & İdil Bilgin Sait & Bulut Yayınları \\
\hline $\begin{array}{l}\text { Müzede Bir Gün-Minik Dostla- } \\
\text { rımız Serisi }\end{array}$ & $\begin{array}{l}\text { Marilita Chatzibodozi } \\
\text { (Çeviren: Aynur Oktay) }\end{array}$ & Pena Yayınları \\
\hline Müzede Canavar Yokmuş & Hüsne Rhea Çiğdem & Çınar Yayınları \\
\hline Öğreniyorum-Müzede Bir Gece & $\begin{array}{l}\text { Pierre De Hugo, Claude } \\
\text { Delafosse, Gallimard }\end{array}$ & Marsık Yayıncılık \\
& $\begin{array}{l}\text { Jeunesse (Çeviren: Me- } \\
\text { lek Didem Boy) }\end{array}$ & \\
\hline Melekler Müzede & Ayça Erdem & Cinius Yayınları \\
Anadolu Kültür Müzesi-Değer- & Alper Yusuf Köroğlu, & Şiir Çocuk Yayınları \\
ler Eğitimi (Kültürel Miraslara & Tamer Uzuner & \\
Sahip Çıkma) & & \\
\hline Çocuk Müzesi Sevincin Sırrı-4 & Necla Ülkü Kuglin & Bilgi Yayınevi \\
\hline Benim Müzem & Emma Lewis (Çeviren: & Redhouse Kidz \\
& Oğuzhan Aydın) & \\
\hline Katie ve Nilüferler & James Mayhew (Çevi- & Yapı Kredi Yayınları \\
& ren: Dilek Erbaş Şeren) & \\
\hline Paris Sanat Macerası-Çocuklar & Melek Oral Koray, Alp & İmge Kitabevi \\
İçin Sanat ve Gezi Rehberi & Gani Oral & \\
\hline Müzedeki Sandık & Nadide Utku & Patikalar Dergisi Yayınları \\
\hline Müze & Susan Verde (Çeviren: & Gün Işığı Kitaplığı \\
& Müren Beykan) & \\
\hline & &
\end{tabular}


Tespit edilen kitaplardan iki tanesinin (Katie ve Nilüferler ile Paris Sanat Macerası-Çocuklar için Sanat ve Gezi Rehberi adlı kitaplar) seri içinde yer aldığ1 görülmüş ve çalışmaya bütün seriyi dâhil etmek yerine serideki kitapların içinden rastgele seçilen birer kitaba yer verilmesi uygun görülmüştür.

\section{Veri Toplama Araçları ve Verilerin Analizi}

Kitaplardan döküman incelemesi yoluyla veriler elde edilmiştir. Döküman incelemesi, araştırılması hedeflenen olgu ve olgular hakkında bilgi içeren yazılı materyallerin analizini kapsar (Yıldırım ve Şimşek, 2008). Elde edilen veriler betimsel analiz ile sunulmuştur. Bu tür analizde amaç, elde edilen bulguları düzenlenmiş ve yorumlanmış biçimde okuyucuya sunmaktır (Yıldırım ve Şimşek, 2008).

\section{Bulgular}

Çalışmada müze kavramını işleyen kitaplar değerlendirilerek okuyucuya kazandırabilecekleri ve müze eğitiminde kullanılma durumları yorumlanmıştır. İncelenen kitaplar müze kavramını ele alış şekillerine göre üç başlıkta sınıflandırılmıştır: Müze Gezisi Odaklı Yazılanlar, Kendi Müzesini Oluşturma Fikriyle Yazılanlar, Etkinlik ve Uygulama Odaklı Yazılanlar. On üç kitaptan yedi tanesi müze gezisi üzerine kurgulanırken üç kitap çocuklarda kendi müzelerini oluşturma fikrini öne çıkarmak için yazılmış, diğer üç kitap ise etkinlikler ve uygulamaya dönük çalışmalarla hazırlanmıştır. Kitaplar ile ilgili tespitler tablolar halinde sunulmuştur.

Tablo 2. Müze Gezisi Odaklı Yazılanlar

\begin{tabular}{|c|c|c|}
\hline Kitabın Adı & Konusu & $\begin{array}{l}\text { Müze Eğitimi Bakımından } \\
\text { Değerlendirilmesi }\end{array}$ \\
\hline $\begin{array}{l}\text { Minik Dostlarımız } \\
\text { Serisi-Müzede Bir } \\
\text { Gün }\end{array}$ & $\begin{array}{l}\text { İskender adlı çocuk kahramanın sınıf } \\
\text { gezisi olarak düzenlenen müze ziyare- } \\
\text { tinde yaşadıkları anlatılır. 2-4 yaş için } \\
\text { uygun olduğu belirtilen kitapta müze- } \\
\text { lerin tarihimiz hakkında bilgi içeren ve } \\
\text { hazineleri koruyan yerler olduğu belir- } \\
\text { tilmiştir. Müze rehberi, tablolar, arke- } \\
\text { olojik eşyalar, heykeller, müze çeşit- } \\
\text { leri hakkında bilgi verilmiştir. }\end{array}$ & $\begin{array}{l}\text { Kurgu içerisinde İskender ve sınıf arka- } \\
\text { daşlarının heykel oyunu oynaması, bir } \\
\text { karton üzerine müzede onları en çok et- } \\
\text { kileyen şeyleri çizmeleri, kilden kendi } \\
\text { sanat eserlerini yapmaları gibi örnek- } \\
\text { lerle müzelerin eğlenceli bir eğitim orta- } \\
\text { mına dönüşebileceği gösterilmiştir. Ay- } \\
\text { rıca müzede sessiz olmanın önemi vur- } \\
\text { gulanarak müze kuralları aktarılmıştır. }\end{array}$ \\
\hline $\begin{array}{l}\text { Müzede Canavar } \\
\text { Yokmuş }\end{array}$ & $\begin{array}{l}10 \text { yaşında hayal kurmayı seven ve } \\
\text { "gündüz düşleri" olan Leyla ve mü- } \\
\text { zede çalışan teyzesinin ilişkisi üzerin- } \\
\text { den kurgulanan anlatıda sanatın insa- } \\
\text { nın kendisini ifade etmede bir araç } \\
\text { oluşu, sanat için hayal gücünün önemi, } \\
\text { müzelerin insanlara yeni ve farklı dü- } \\
\text { şünceler kazandırmadaki gücü vurgu- } \\
\text { lanmıştır. Leyla'nın teyzesi hem Müz } \\
\text { adlı peri hem de kitabın yazarıdır ve } \\
\text { Leyla'nın müze gezisine eşlik eder. }\end{array}$ & $\begin{array}{l}\text { Leyla duygularını ifade edemediğinde } \\
\text { sessiz kalmak, ağlamak, öksürmek gibi } \\
\text { davranışlarda bulunur, kurguda bunlar } \\
\text { yerine resim yapma önerisine yer verilir } \\
\text { ve böylece sanat eğitiminin olumlu, iyi- } \\
\text { leştirici ve pedagojik etkisi öne çıkarılır. } \\
\text { Müze gezerken uyulması gereken kural- } \\
\text { lar, emrivaki değil, nedenleri açılana- } \\
\text { rak ve ikna edici bir dille verilmiştir. } \\
\text { Modern sanat müzesinde geçen gezide } \\
\text { "tuval, portre, otoportre, künye, }\end{array}$ \\
\hline
\end{tabular}


naturmort, soyut resim" gibi terimlere yer verilmiş ve koyu harflerle yazılmış bu terimler tanımlanarak okuyucunun kelime dağarcığına katkı sunulmuştur. Işık olmadan işe yaramayan fotoğraf sanatı, üç boyutlu yönüyle resimlerden ayrılan heykeller, video sanatının gelişimi, yerleştirme sanatı hakkında bilgi verilmiştir. Müzeler insanlar için büyük bir öğrenme alanı olarak gösterilmiş, sınırsız ve özgür bakış açısı geliştirmede etkili olacağı dile getirilmiştir.

Sınıflarıyla veya aileleriyle gelip müzeleri gezen çocukların varlığı kurguda yer alırken kitabın sonunda modern ve çăgdaş sanat çalışmaları sergileyen bazı müzeler ve sanat kurumlarına (İstanbul, Ankara, Eskişehir, Bayburt gibi şehirlerde) yer verilerek okuyucular müze gezisi için teşvik edilmiştir.

Müze Müze gezen genç bir kızın gördüğü sanat eserlerinden etkilenişi işlenir. Müzeyi bazen düşünceli, bazen mutlu, bazen korkulu, bazen kasvetli bir ruh hali ile ama hep eğlenerek gezer. Gördüğü boş tuvalle ise adeta hayal gücünü harekete geçirir.

Melekler
Müzede-Çocuklar
için Sanat Kitabı
için Sanat Kitabı
Öğretmenleri eşliğinde okul gezisi için müzeye gelen meleklerin deneyimleri anlatılır. Leonardo Da Vinci, Boticelli, Modigliani, Degas, Frida Kahlo, Monet, Gaugin, Gustave Klimt, Salvador Dali gibi birçok ünlü ressama ve tablolarına ait bilgi verilir.
Katie ve Nilüferler Katie ve büyükannesi sanat galerisi gezerlerken Monet Çocuk Resim Yarışması olduğunu görürler ve Katie yarışmaya katılarak şansını denemek ister. Fikir edinmek için Claude Monet'in sergilerini gezerken kendini tablonun içinde bulur. Monet'in tabloları içinde maceralar yaşar ve boya takımı hediyesi olan yarışmayı kazanır.
Müzede zaman geçirmekten zevk alan bir kız çocuğu karakterize edilerek okuyucular üzerinde sanat müzelerine olumlu bakış geliştirilmeye çalışılmıştır. Van Gogh, Picasso, Rodin gibi ünlü sanatçıların eserlerine yer verilerek okuyucunun hayal dünyasına sesleniş vardir.

Müzeye girişte bilet alınması ve iki meleğin gruptan ayrılarak tabloların altında yazan bilgilere göre tek başına geziyi sürdürebilmeleri okuyucuda müze bilinci uyandırmada etkili olabilecek niteliktedir.

Kurguda gezi sonunda meleklerden sanat okuluna gitmeye karar verenler olması okuyucu için de olumlu bir modellemedir.

Müzeler ilham verir, sanatçı bakışını destekler iletileri verilir. Tabloları keşfetmeyi sağlayan bir kitaptır. Benzer amaçla yazılmış beş kitap (Serideki diğer kitaplar; Katie ve Ayçiçekleri, Katie ve İzlenimci Ressamlar, Katie ve Y11dizlı Gece, Katie ve Dinozorlar, Katie ve Mona Lisa) daha bulunmaktadır. 


\begin{tabular}{|c|c|c|}
\hline Müzedeki Sandık & $\begin{array}{l}\text { Öğretmen eşliğinde çıkılan müze gezi- } \\
\text { sinde } 10 \text { yaşındaki Gökhan ve } 9 \text { yaşın- } \\
\text { daki Fulya adlı ana kahramanlar sıkılıp } \\
\text { gruptan ayrılarak kendileri gezerler. } \\
\text { Rahatça gezmek için sandığın içine } \\
\text { saklanırlar ve kendilerini bilmedikleri } \\
\text { bir yerde, Duru'nun } 8 \text {. yaş günü kutla- } \\
\text { masında bulurlar. Yetişkinlerin tepki- } \\
\text { sizliği ve ifadesizliği, robotlaşmaya } \\
\text { benzer tavırlarını dikkatlerini çeker ve } \\
\text { Duru'nun babaannesi Sevim Nine'den } \\
\text { onların kalplerinin yerinde koca bir } \\
\text { boşluk olduğunu öğrenirler. Bu du- } \\
\text { ruma } 40 \text { yıl öncesinde sönmüş yıldız- } \\
\text { lardaki cüceler sebep olmuştur. } 10 \text { ya- } \\
\text { şına girenler duygularını kaybeder ve } \\
\text { sadece akılllarıyla hareket etmeye baş- } \\
\text { larlar. Gökhan gölgesi olmayan gözle- } \\
\text { rin sahibidir ve her şeyin eski haline } \\
\text { gelmesi için Enci adlı şirin cücenin } \\
\text { sorduğu bir bilmeceyi bilmesi gerekir. } \\
\text { Gölgesi olmayan iki şey bulacaktır; } \\
\text { biri kendinde, biri kendi dışındaki her } \\
\text { şeydedir. Cevaplar: gölge ve 1şıktır. } \\
\text { Kurgunun sonunda Enci ve Gökhan } \\
\text { 1şık olup gökyüzüne uçarlar. Müzeye } \\
\text { dönüş yine Sevim Nine'nin sandığının } \\
\text { içine girerek gerçekleşir. }\end{array}$ & $\begin{array}{l}\text { Bir müze gezisinde başlayan anlatıda } \\
\text { geçmişe yolculuk söz konusudur. Gittik- } \\
\text { leri yerde geçmişe ait eşyalar ne kadar } \\
\text { değerli olursa olsun bir işe yaramaya- } \\
\text { cakları düşüncesiyle müze yoktur. Ters } \\
\text { mantık kurularak müzelerin değeri sez- } \\
\text { dirilmiştir. }\end{array}$ \\
\hline Müzede Bir Gün & $\begin{array}{l}\text { Annesinin yağmurlu bir günü değer- } \\
\text { lendirme fikriyle resim müzesine gö- } \\
\text { türdüğü Bulut önce müzeyi çok sıkıcı } \\
\text { bulur çünkü müzede her şey (çimlere } \\
\text { basmak, koşmak, bir şeyler yemek iç- } \\
\text { mek, fotoğraf çekmek, tablolara do- } \\
\text { kunmak vb.) yasaktır. Bu sıkıcı gezi, } \\
\text { müzede karşılaştığı bir başka çocuk sa- } \\
\text { yesinde değişir. Ada tablolardan ken- } \\
\text { dine göre güzel anlamlar çıkartarak ge- } \\
\text { ziyi eğlenceli hâle getirir. Resim çiz- } \\
\text { mek, hayal gücü ile tablolardaki kişi- } \\
\text { leri farklı hayal etmek, tabloda gör- } \\
\text { düğü çizimlerle kendi hayatı arasında } \\
\text { bağ kurmak, benzerlikleri fark etmek } \\
\text { gibi. Bulut da tabloların ona hatırlat- } \\
\text { tıklarını düşünerek ve en sevdiği tablo- } \\
\text { ları seçerek gezmeye devam eder ve } \\
\text { gezi daha eğlenceli hâle gelir. }\end{array}$ & $\begin{array}{l}\text { Müzeyi sevmeyen bir çocuğun ön yargı- } \\
\text { larının kırılması işlenmiştir ve okuyucu } \\
\text { için bu durum modellenebilir bir örnek- } \\
\text { tir. } \\
\text { Müze görevlisi ortada yokken Bulut ve } \\
\text { Ada'nın çantalarından çıkardıkları mey- } \\
\text { veleri yemeleri müze kuralları bakımın- } \\
\text { dan olumsuz bir davranış örneğidir. } \\
\text { Kitabın sonunda kitapta tablosu yer alan } \\
\text { yerli ve yabancı sanatçılar (Hale Asaf, } \\
\text { Osman Hamdi Bey, Vincent van Gogh, } \\
\text { Paul Gaugin, Paul Cezanne, Claude Mo- } \\
\text { net, Vasily Kandinsky vb.) hakkında } \\
\text { bilgi verilmesi ve kitapta yer alan resmin } \\
\text { künyesinin belirtilmesi eğitici ve güzel } \\
\text { bir yaklaşımdır. }\end{array}$ \\
\hline
\end{tabular}

Müze gezisi öncesinde öğrenciler zihnen geziye hazırlanmalıdır. $\mathrm{Bu}$ merhalede öğrencilere, gezilecek müze ve müzede keşfedilecek nesnelerle ilgili merak uyandırıcı ön bilgiler verilmelidir. Öğrencilere müze gezisi kuralları hatırlatılmalıdır (İMEM, 2011). Tablo 2'de görüldügü üzere incelenen kitapların çoğunluğu müze gezisi odaklı olarak kurgulanmıştır. Müze eğitiminde istenen bir durum olan bu ziyaretler öğretmen veya ebeveyn eşliğinde yapılabileceği gibi yaş grubuna göre akranlar ile veya bireysel de 
gerçekleştirilebilir. İncelenen kitaplarda müze gezisine öğretmen, anne, teyze, büyükanne gibi büyükler eşlik etmekle beraber kurgu içinde gezi daha çok arkadaşlar ile veya bireysel tamamlanmaktadır. Bu durum çocuklarda müze kültürü ve bilinci oluşturmak adına faydalı olacaktır. Gezilerde müzelerde uyulması gereken kuralların aktarımına da yer verilmektedir. Melekler Müzede-Çocuklar için Sanat Kitabı adlı kitapta "Öğretmenleri onlara, müzelerde yüksek sesle konuşmanın ve etrafta koşturmanın uygunsuz olduğunu öğretmişlerdi." (Erdem, 2014) ifadesi ile müze kuralları hatırlatılır. Müzede Canavar Yokmuş adlı kitapta kurallara uymanın önemi ikna edici ve açıklayıcı bir dille anlatılırken Melekler Müzede-Çocuklar için Sanat Kitabı'nda müzeye giriş için bilet almak gerekliliği belirtilmiştir. Sadece Müzede Bir Gün adlı kitapta müze kurallarının dışına çıkılmış, kahramanlar müze görevlisi görmeden müzede meyve yemişlerdir. Müze eğitimi bakımından istenmeyen bir iletiye yer verilmiştir.

Atagök'e (1982) göre ise çağdaş müzeler, gelen ziyaretçilerin eğlenirken öğrendiği ve öğrenmekten zevk aldığ 1 kültür merkezleridir. İncelenen kitaplarda müzelerin eğlenerek öğrenmeye uygun eğitim ortamları olarak öne çıkarıldığı görülmektedir. Müzelerin eğlenceli yerler olduğu ve hayal gücünü geliştirdiği tüm eserlerde yer bulmuştur. Minik Dostlarımız Serisi-Müzede Bir Gün adlı kitapta müzelerin eğlenceli olduğu fikri "Müzeler hiç de sıkıcı değildi. Oyun ve eğlence dolu bir yolculuk geçirmişti. İskender bir sonraki müze ziyaretini sabırsıllıkla bekliyordu." (Chatzibodozi, 2018) ifadeleriyle verilirken Müze adlı kitapta yer alan "Öyle harika zaman geçirdim ki: Korktum, şaşırdım, çıldırdım, sevinç duydum. Enerji doluyum baştan aşağı." (Verde, 2020) ifadeler de benzer bakış açısındadır. Melekler Müzede-Çocuklar için Sanat Kitabı adlı eserde "Bir günde ne çok şey ögrenmişlerdi, hayal güçleri artmıştı." (Erdem, 2014) ifadesi ile müzelerin çocukların hayal gücüne olan olumlu etkisi vurgulanır. Müzedeki Sandık adlı kitapta ise aynı durum "Gökhan, gezdiği müzeleri hatırlamış. O gezintiler sayesinde ne kadar çok düş kurduğunu hatırlamış ve buradaki çocuklar için üzülmüss.” (Utku, 2015) ifadeleriyle verilir. Katie ve Nilüferler adlı eserde çocuk kahramanın tabloların içine girerek hayallere dalıp eğlenceli bir sanat yolculuğuna çıkışı anlatılırken $M \ddot{u}$ zede Bir Gün adlı eserde çocuk kahramanın müzenin sıkıcı olduğuna dair ön yargıları ortadan kalkar, Müzede Canavar Yokmuş adlı eserde ise hayal gücü ile müze sevgisi pekiştirilir. Müze adlı kitapta yer alan "Müze geceleri kapal,, ama sorun değil benim için. Gördügüm her şeyde etkisi sürüyor. Müze benim 
içimde yaşlyor." (Verde, 2020) ifadeleri de müze sevgisine ve müzenin çocukların gelişimine olan katkısına örnektir.

Müzede Canavar Yokmuş adlı kitapta; "Müzeler bilgi bakımından bir hazine gibidir." (Çiğgem, 2019) denerek müzelere olumlu bir bakış oluşturulmaya çalışılmıştır. Yine aynı kitapta özdeşim kurmaya uygun bir karakter üzerinden sanat bakış açısı da öncelenir: "Leyla için resim yapmak su içmek, yemek yemek gibi bir şeydi." (Çiğdem, 2019) Sanatın “anlaşılmaz” gibi görünen yüzünde sanatseverin sabrının ve sanatçının iç dünyasını, iç sesini yansıtmasının etkisi olduğu iletisi verilerek müzelerin aslında derinlik taşıyan ve üzerine düşünüldüğünde anlam kazanan eserlerle dolu kurumlar olduğu vurgulanmıştır. Sanat; "özgür olmak, istediğin şeyi istediğin şekilde, saklamadan dile getirmek" olarak ifade edilmiş ve sanatın insanlığa farklı bakış açılarını görme, farklı fikirlere saygı duyma noktasında katkıda bulunması "tek bir renkte farklı yolculuklara çıkabilme" olarak örneklenmiştir. "Sanatçılar insanların alışılagelmişs şeyleri sorgulamasına da sebep olabilirmiş." (Çiğdem, 2019: 39), "Sanki dünyayı başka şekillerde gösteren gözlüklerle dolaşmak gibi değil mi modern sanat müzesinde gezmek?” (Çiğdem, 2019) ifadeleri de örnektir. Kitapta ayrıca birçok sanat terimi açıklanarak okuyucunun kelime dağarcığına katkı sağlanmıştır.

\section{Tablo 3. Kendi Müzesini Olușturma Fikriyle Yazılanlar}

\begin{tabular}{|c|c|}
\hline Kitabın Adı & Konusu \\
\hline $\begin{array}{l}\text { Benim } \\
\text { Müzem }\end{array}$ & $\begin{array}{l}2017 \text { yılında Bologna Çocuk Kitapları Fuarı tara- } \\
\text { fından ilk eserlere verilen Opera Prima ödülünü } \\
\text { alan kitapta küçük bir kızın müzeleri, müze çeşit- } \\
\text { lerini keşfi anlatılmıştır. } \\
\text { Tarihi eserler müzesi, doğa tarihi müzesi, sanat } \\
\text { müzesi, açı hava müzesi, uzay müzesi, bitki mü- } \\
\text { zesi, deniz canlıları müzesi, kuş müzeleri hakkında } \\
\text { bilgi verilir. En sevdiğim şeylerle dolu ve en iyi } \\
\text { bildiğim yer kendi müzem diyen karakterin tavrı } \\
\text { okuyucu için özendirici niteliktedir. }\end{array}$ \\
\hline
\end{tabular}

\section{Müze Eğitimi Bakımından}

Değerlendirilmesi

Müze çeşitleri hakkında bilgi vermesi yönüyle öğretici bir nitelik taşıyan kitap müzelerin eski olmak zorunda olmadığını ve müzelerde herkesin ilgisini çekebilecek şeylerin olduğunu da vurgular.Anlatı sonunda yer alan şu sorularla okuyucu müzecilik üzerine düşündürülmeye çalışmıştır: "Ne koleksiyonu yapmayı seversin?, Kendi müzende neler sergileniyor?, Ziyaret edebileceğin başka ne tür müzeler var?, Başka nelerin müzesi olabilirdi sence?, Antik oyuncak hayvanların kime ait olduğunu tahmin edebilir misin?, Buraya birkaç antik oyuncak çizebilir misin?, Sanat Müzesi'nde en sevdiğin resim hangisiydi?, Buraya resimler çizip kendi galerini oluşturmak ister misin?".

Anadolu MEB Talim ve Terbiye Kurulu Bakanlığınca kabul Kültür edilen Okul Öncesi Eğitim Programına uygun olaMüzesiDeğerler Eğitimi (Kültürel Miraslara Sahip Ç1kma) rak hazırlanan kitapta Sema adlı çocuk kahraman televizyonda halk oyunları gösterisini izler ve etkilenir. Öğretmenin de desteğiyle sınıfça bir halkoyunu ekibi oluştururlar. Tüm çocuklar evde aileleriyle proje hazırlarlar. Kültürel mirası yansıtan ürünleri okulda birbirleri ile paylaşırlar. Bezden bir bebek, Türk kültürüne ait fotoğrafların olduğu bir
Çocuklara kendi müzelerini oluşturma fikri hâkimdir. Yaparak ve yaşayarak öğrenme fikri bağlamında değerlerimize ve müze eğitimine yönelişs söz konusudur. 
albüm, kil hamurundan tarihi eser maketi gibi ürünleri okul bahçesinde Anadolu Kültür Müzesi adıyla sergilerler.

Çocuk Sevinç Teyze adlı başkahramanın yazlıktaki ço-

Müzesi- cuklara yeni ve yaratıcı fikirlerle gelerek onları eğ-

Sevincin lendirmesi işlenir. Resim yapmak, sergi açmak, Sırrı 4 maskeli balo yapmak, birlikte yemek yemek, gü-

Romana yaparak ve yaşayarak öğrenme fikri hâkimdir. Çocuk Müzesi projesi orineş tutulmasını izlemek için motor yolculuğu yapmak, Kızılderili oyunları oynamak gibi etkinliklerle çocukların tatillerini güzelleştirir. Arkadaşlariyla çocuk müzesi açmak isteyen Sevinç Teyze unutulan çocuk oyunlarını araştırmayı ve canlandırmayı, çocuk kitaplarının ve dergilerinin bulunduğu bir yer oluşturmayı amaçlar. Çocukla ilgili her şeyi sergilemek (giysi, oyuncak, beşik, mama takımı, geleneksel olan şeyler) niyetindedir. Normal bir müzede koruma amaçlı hiçbir şeye dokunmama fikrini tersine çevirmek için "Sus, dur, otur, yapma" gibi emir cümlelerinin olmayacağı bir müze tasarlar. Çocukların doğasındaki hareketliliğe uygun, sergilenen kıyafetlerin giyilmesi, eşyaların oyun malzemesi olması gibi yaparak ve yaşayarak öğrenme fikri vurgulanır. Projeye göre bir günlüğüne herkes para verip müzeyi gezebilecektir, çocuk kulübü de bulunan müzenin üyeleri her zaman her şeye katılabilecek ve müzeyi onlar yönetecektir. Ankara'da olması planlanan müzede her çeşit malzemeyle el işi ürünler yapılacaktır.

Bulut ve Atilla'ya (2017) göre öğrenci aktif öğrenme sürecinde yaparak yaşayarak ilkesinden hareketle sınıf ortamından çıkarılarak, eserlerle etkileşim içinde olabileceği ortamlarda eğitim-öğretim sürecine dâhil edilmelidir. Tablo 3 'te incelenen eserlerde çocuklara kendi müzelerini oluşturma fikri verilmek istenmiştir. Üç kitapta da ortak olan fikir çocukların kendileri için değerli olan veya ilgi alanlarına giren ürünleri biriktirerek veya kendileri üreterek müzecilik kavramını yaparak ve yaşayarak edinmeleri olmuştur. Böylece müzelerin çocuklar için daha anlamlı ve ilgi çekici yerler olması muhtemeldir.

Benim Müzem adlı kitapta "Müzeler dünyanın dört bir yanından toplanan en eski ve en ilginç şeylerin sergilendiği büyük binalardır." (Lewis, 2019) bilgisi ve bir otobüs görselinin üzerinde doğrudan "Müzeleri Ziyaret Edin!" (Lewis, 2019) iletisine yer verilir. Ayrıca müzelerin sadece tarihî eserleri içermediği, her türlü ilgi alanına ait müze çeşidi olduğu bilgisi verilerek çocukların müzelerin sıkıcı olduğuna dair ön yargısı kırılmaya çalışılmıştır.

Dünyada ve Türkiye'de çocuk müzelerinin varlığı sayesinde çocuklar; yetişkin dünyasından uzak, kendi anlam alanına uygun bir şekilde müzeleri ziyaret edebilmektedirler ve bu durum oldukça sevindiricidir. Çocuk MüzesiSevincin Sırrı 4 adlı kitapta "Bütün dünyada var bu müzelerden çünkü artık çocuklar ciddiye alınıyor.” (Kuglin, 2001) denilerek çocuk müzelerine dikkat 
çekilmiştir. Ayrıca kitapta yer alan “Biz de mutlaka Türkiye’de gerekli gördük böyle bir şeyi. Çünkü bizim çocuklarımız çok disiplinli: önlük giyiyor, izin almadan sınıfta dolaşamıyor, çok az spor yapıyorsunuz. Ders yaparken bile konuşma firsatını olmuyor: anlatılanı dinleyip sorulara cevap veriyorsunuz. Hatta, onu bile yapamıyorsunuz, seçmeli cevap kağıdında, doğruyu bulup işaretliyorsunuz. Siz de kendi müzelerinize gelip soru soracaksınız, araştıracaksınız, kurcalayarak, bozarak ögreneceksiniz!’' (Kuglin, 2001) ifadeleri ile yapılandırmacı yaklaşıma olan yönelim ve müze eğitiminin bu açıdan etkisi vurgulanmaktadir.

Müzeler sadece bir ulusun geçmiş tarihini yansıtmaz, birlikte yaşamakta olduğumuz değerleri tanımlamaya ve onları bir anlama koymamızı da sağlarlar (Mercin, 2006). Anadolu Kültür Müzesi-Değerler Eğitimi (Kültürel Miraslara Sahip Çıkma) adlı kitapta okul öncesi dönemde bu bilinç aktarılmaya çalışılmaktadır.

\section{Tablo 4. Etkinlik ve Uygulama Odaklı Yazılanlar}

\begin{tabular}{ll}
\hline Kitabın Adı & Konusu \\
\hline Öğreniyorum- & Paleontoloji odasındaki dinozor iskelet- \\
Müzede Bir & leri, Mısır mezarlarına ait kalıntılar (la- \\
Gece & hitler, maskeler vb.), heykeller (taştan, \\
& ahşaptan, topraktan, kemikten yapılmış), \\
& ünlülerin resimlerinden örnekler (Mona \\
& Lisa, Madam Recamier), gökyüzü ve \\
& uzay araştırmalarıyla ilgili eserler, deniz \\
& ve okyanuslarda yaşayan canlılar kitapta \\
& yer alır.
\end{tabular}

Konya'da İz 9-11 yaş aralığındaki Eren, Arda, Nazlı, Peşinde Duru adlı çocuk kahramanların kendilerini ve ardından konservasyon terimini tanıtmaları ile başlar. Kitapta okuyucuların 7 etkinlik tamamlayıp 5 harfli bir şifrenin izini sürerken Konya'nın kültürel mirasından bir kesit öğrenmeleri amaçlanmıştır. Duvar resmi, İvriz Kaya anıtıhiyeroglif-fotoğraf inceleme, Çini duvar mozaiği (yapboz tarzı ve mıknatıslı), Ahşap pencere kanadı gibi sanatsal etkinlikler vardır. Somut olmayan kültürel miras: bastırık (yöresel bir yemek), Nasreddin Hoca fikraları, Konya türküleri, Mevlana felsefesi, çinicilik, halıcılık ve Konya adının efsanevi adlandırılış (İkoniumKuuniye-Konya) hakkında da bilgi verilmiştir. Bulunması istenen şifre Zeus'un oğlu Perseus'un yendiği ejderhaya benzer canavar Medüz'dür.

Paris Sanat 20 çocuk ile gerçekleştirilen gezide PiMaceras1- casso Müzesi, Notre Dame, D'Orsay

\section{Müze Eğitimi Bakımından}

Değerlendirilmesi

Okul öncesi ve ilköğretim ön sınıftaki çocuklar için ilk bilimsel öğreti kitapları serisinde yer alan kitabın son sayfasında kâğıttan yapılmış fener yer almaktadır. Feneri yerinden çıkartıp siyah sayfa ile saydam sayfa arasına koyarak müzedeki eserleri aydınlatma ve inceleme fikri oldukça eğlenceli bir etkinliktir. Okuma eylemi bittikten sonra okuyucudan tanitılan sanat eserlerini bulması istenerek bir nevi öğrenme pekiştireci sağlanmaktadır.

Koç Üniversitesi VEKAM 2015 Araştırma Ödülü'nü alan kitap kültürel mirasın korunmasını çocuklar için eğlenceli bir konuya dönüştürmeye yönelik hazırlanmıştır. Kitabın ön kapağında kitaptaki etkinliklere rehberlik edecek kılavuz kâğıtlar ve karton fener bulunmaktadır. Saydam sayfalar karton fenerle incelendiğinde daha anlamlı hale gelmektedir. Kitabın sonunda yer alan mini sözlük, terimler ve kitap okunduktan sonra doldurulması için boş bırakılan tanımlanmamış kelimelerin varlığı okuyucuya kelime öğretiminde fayda sağlayacak niteliktedir. Yeni neslin dikkatini çekecek şekilde oluşturulan kitabın sonunda cevap anahtarının mobil uygulamaya dönük bir karekod ile verildiği görülmektedir. Yapılandırmacı yaklaşıma, yaparak ve yaşayarak öğrenmeye uygun olarak tasarlanmış bir kitaptir.

Kitap, dünyanın önemli kültür, sanat ve bilim merkezlerine gidecek ailelere yaratıcı ve 
Çocuklar Müzesi, Louvre, Quai Branly, Orangerie için Sanat Müzesi, Pompıdeu Müzesi, Rodin Müve Gezi zesi görülmüştür. Monet, Manet, Renoir, Rehberi Degas gibi izlenimcilerin çizimlerine yer verilmiştir. Paris ve hayat, yemekler, moda, metro gibi ek bilgiler de var. doğru rehber olmayı ilke edinmiştir. Geziye katılan çocukların gözünden günlük yorumlarına ve çizimlerine yer verilmiştir. Okuyucuya da çizimlerde bulunması için sayfalar hazırlanmıştır. Gezi sonrası eve dönen çocuklar sanat atölyesinde en çok etkilendikleri şeyleri de kâğıda dökerler. Anılar, resimler, günlüklerle oluşturulan bir kitaptır. (Serideki diğer kitaplar şunlardır: Barcelona Sanat Maceras1, İstanbul Sanat Maceras1, Floransa Venedik Sanat Macerası, Roma Sanat Macerası, New York Sanat Maceras1.)

Eğitim amaçlı bir müze gezisi için; tema, amaç ve eğitimsel kazanımlar belirlenmelidir. Müze gezisi, bu amaç ve eğitimsel kazanımları gerçekleştirmek üzere gezi öncesi etkinlikleri, müze gezisi ve gezi sonrası etkinlikleri olmak üzere üç merhalede planlanır. Uygulamanın her merhalesi, gezinin amaç ve kazanımlarına uygun içerik, yöntem ve malzemelerle gerçekleştirilmelidir (İMEM, 2011). Tablo 4'te incelenen eserler bu anlamda kullanılmaya uygun kitaplardır, müze gezisinin üç merhale de eşlik edecek argümanlar barındırmaktadırlar. Bu kitaplarda bir kurgu metni bulunmamakla beraber müze eğitiminin uygulanabilirliği ve etkinliklerle eğlenceli bir hâl alacağı ortaya konmuştur. Çocuklara bir keşif ve macera ortamı sunularak müzelere ve sanat eserlerine olan ilgi artırılmaya çalışılmıştır.

Öğreniyorum-Müzede Bir Gece ve Konya'da İz Peşinde adlı eserlerde saydam sayfalar üzerinde verilen sanat eserlerini karton fener ile inceleme fikri ortaktır. Bu fikir çocukların müzelere olan merakını destekleyici ve sanat eserlerini incelemeye yönlendirici niteliktedir. Konya'da İz Peşinde adlı kitapta okuyucunun kelime dağarcığını geliştirmeye yönelik sözlüğe ve boşluk doldurma etkinliklerine yer verilmiştir. Ayrica bu kitap incelenen eserler arasında çağımız çocuklarının dikkatini çekebilecek karekod uygulamasına yer veren tek kitaptır. Paris Sanat Macerası-Çocuklar için Sanat ve Gezi Rehberi çocukların müze gezisi sırasında ihtiyacı olan bilgileri içermesinin yanı sıra bir günlük ve anı defteri gibi kullanabileceği şekilde hazırlanmıştır. Böylece sadece okuma becerisini değil yazma becerisini de işe koşan ve çocukların müze gezilerine olan ilgisini pekiştiren bir kitaptır.

\section{Sonuç ve Öneriler}

Müzeler geçmişi gözler önüne sererken bilgi aktarmayı başaran, bugün ile karşılaştırma yapmamızı sağlayan, birden fazla duyumuza hitap ederek algımızı canlı tutan ve estetik yönümüze hitap eden eğitim mekânlarıdır. Yapılandırmacı anlayış ile aynı bakış açısını benimseyen, yaparak ve yaşayarak 
öğrenme için okul dışında seçilebilecek kıymetli eğitim alanlarından biri olan müzeler eğitimde yeni bir soluk olarak görülmüş ve gerek Millî Eğitim Bakanlığına bağlı kademelerde öğrenciler için gerekse üniversitelerde öğretmen adayları için değeri anlaşılan, etkinliklerle örülü bir saha hâline gelmiştir. 2020'li yılları yaşarken okulöncesi, ilköğretim, ortaöğretim ve yükseköğretim olmak üzere eğitimin tüm kademelerinde müze eğitimine yönelik uygulamalar yerini sağlamlaştırmaktadır.

Çocuk edebiyatında müze eğitimi de yazılan çocuk kitapları ile dikkat çekici bir kimlik kazanmaya başlamıştır. Çalışmada incelenen kitaplar müze eğitimi bakımından uygun nitelikler taşımaktadırlar. Yapılan incelemede kitaplar; müze gezisi odaklı yazılanlar, kendi müzesini oluşturma fikriyle yazılanlar, etkinlik ve uygulama odaklı yazılanlar olmak üzere üç başlıkta sınıflandırılmıştır. Kitapların çoğunluğu bir müze gezisinde uyulması gereken kuralları kurgu içinde aktarmayı başarırken müzelerin eğlenceli ve hayal gücünü harekete geçiren mekânlar olduğunu da öne çıkarmışlardır. Kitaplarda özdeşim kurmaya uygun çocuk kahramanların varlığı, çocuklara ilgileri doğrultusunda kendi müzelerini kurma fikrinin verilmesi, etkinliklerle örülü eğlenceli uygulamaların hazırlanması müze eğitimini destekleyici özelliklerdir. Kitapların dünyadaki (Örneğin; Paris Sanat Macerast-Çocuklar için Sanat ve Gezi Rehberi) ve ülkemizdeki (Örneğin; Konya'da İz Peşinde) sanat eserlerine ve müzelere yer vermesi de farklı kültürlere, medeniyetlere dönük bakış açısı oluşturmada olumlu bir durumdur.

Müzelerin sıkıcı yerler olmadığı ve aslında sanatın insanın duygularını aktarmada güçlü bir araç olduğu fikri incelenen çocuk kitaplarında işlenmiştir. Müzelere ve sanat eserlerine yönelik geliştirilen anlaşılmazlık duygusunun çocuklarda oluşturduğu ön yargılar bu kitaplar aracılığıyla kırılacaktır. Kitaplarda sanat eserlerine dair görsellere ve bilgilere yer verilmesi, ressamların tanıtılması estetik gelişimi sağlarken kültürümüze ait eserleri keşfetmeye ve korumaya yönelik bilgilerin verilmesi de değerler eğitimine hizmet etmektedir. Öğretmen ve ebeveynler eşliğinde okunmaya ve uygulanmaya olanak sağlayan kitapların müze eğitimi için uygun nitelikte olduğu görülmüştür.

Çocukların sanat yolculuğunda çocuk kitaplarının yeri vazgeçilmezdir. Çalışmada incelenen kitaplar çocuklar için birer "müze rehberi" kabul edilebilir. Geçmişimizi temsil eden müzelerle geleceğimizi şekillendirecek olan çocukları tanıştırmada çocuklar için yazılmış kitaplarla güzel bir ilişki temellendirilebilir. Bu kitaplarla çocuklara hem Türk kültürünü hem de dünya 
üzerindeki birçok farklı kültürü tanıma firsatı sunulabilir. Bir yandan millî değerler bilinci aktarılırken diğer yandan farklı kültürlere saygı duymanın önemi öğretilebilir. Okul öncesinde ve ilköğretim dönemindeki çocuklar için müze gezisi öncesi hazırlayıcı mahiyet taşıyabilecek olan kitaplar öğretmenler tarafindan eğitim ortamında bir materyal hâlini alabilir veya aileler için çocuklarıyla eğlenceli ve kaliteli zaman geçirme aracı hâline getirilebilir. Okul dışı ögrenme ortamlarında yer verilen müze ziyaretlerinde çocuğun müzeler ve çeşitleri hakkında bilgi edinmesini sağlamak, müze gezintisi esnasında dikkat edilmesi gereken kurallar hakkında bilgi aktarımı yapmak amacıyla bu kitaplardan yararlanılabilir. Kitapların müzeye karşı bir ilgi ve sevgi oluşumunda da işe yarayacağı öngörülmektedir. Aktif öğrenme ve deneyim kazanmak için uygun eğitim ortamları olan müzelerde etkinlik ve uygulama odaklı yazılan kitaplardan fayda sağlanabilir.

\section{Kaynakça}

Abacı, O. (1996). Müze eğitimi. Sanatta yeterlilik tezi. Marmara Üniversitesi Sosyal Bilimler Enstitüsü Resim İş Ana Sanat dalı.

Abacı, O. (2005). Çocuk ve müze. İstanbul: Morpa Kültür Yayınları.

Alakuş, O. A. (2005). Sanat eğitiminin kuramsal temelleri. V. Özsoy, (Ed.), Illköğretim sanat eğitimi kuramları ve yöntemleri içinde (21-31). Ankara: Görsel Sanatlar Eğitimi Derneği.

Atagök, T. (1982). Çağdaş müzecilik kavramı doğrultusunda Türk sanat müzelerinin kültürel etkinliklerinin saptanması. Yeterlilik tezi, Mimar Sinan Üniversitesi Sosyal Bilimler Enstitüsü.

Bulut, Ü. ve Atilla, U. (2017). Müze eğitiminin çocuğun görsel sanatlar eğitimine etkileri. Ordu Üniversitesi Sosyal Bilimler Araştırmaları Dergisi, 7(3), 705-714.

Chatzibodozi, M. (2018). Minik dostlarımız serisi-Müzede bir gün (A. Roussou, İllus.). (A. Oktay, Çev.). İstanbul: Pena Yayınları. (Orijinal çalışma basım tarihi 2017.)

Çakır-İlhan, A., Artar, M., Bıkmaz, F., Okvuran, A., Tezcan-Akmehmet, K., Doğan, D., Karadeniz, C., Çiğdem, H. ve Kut, S. (2019). Müze ĕgitimi. Ankara: MEB.

Çiğdem, H. R. (2019). Müzede canavar yokmuş (2.baskı) (O. Gülfidan, İllus.). İstanbul: Çınar Yayınları.

Erdem, A. (2014). Melekler müzede-Çocuklar için sanat kitabı (P. Bingül Göksun, İllus.). İstanbul: Cinius Yayınları.

Göğebakan, Y. (2016). Üniversiteler ve müzeler: İnönü Üniversitesi müzeleri. SDÜ ART-E Güzel Sanatlar Fakültesi Sanat Dergisi, 9(18), 470-489.

Ilıcak-Aydınalp, Ş. G. (2019). Müze iletişimi. İstanbul: Akademik Kitaplar.

İstanbul İl Milli Eğitim Müdürlüğü. (2011). Müze eğitimi. http://www.turob.com/Resources/doc/\%C4\%B0stanbul $\% 20 \mathrm{MEM} \% 20 \% 20 \mathrm{M} \% \mathrm{C} 3 \%$ BCze $\% 20 \mathrm{E} \% \mathrm{C} 4 \% 9$ Fitimi.pdf

Karadeniz, C. ve Okvuran, A. (2014). Müzede bir gece: Ankara Üniversitesi öğrencileri ile Çorum Arkeoloji Müzesi'nde müze eğitimi. Elementary Education Online, 13(3), 865-879. 
Karasar, N. (2012). Bilimsel araştırma yöntemi. Ankara: Nobel Yayınları.

Kuglin, N. Ü. (2001). Çocuk müzesi-Sevincin sırrı 4 (C.Yaren, İllus.). Ankara: Bilgi Yayınevi.

Kuruoğlu-Maccarı, N. (2002). Müzelerin eğitim ortamı olarak kullanımı. Eğitim Fakültesi Dergisi, 15(1), 275-285.

Lewis, E. (2019). Benim müzem (2. baskı) (E. Lewis, İllus.). (O. Aydın, Çev.). İstanbul: SEV Yayıncılık. (Orijinal çalışma basım tarihi 2016.)

Mercin, L. (2006). Müzeler ve toplum. https://www.ayk.gov.tr/wp-content/uploads/2015/01/Yrd.-Do\%c3\%a7.-Dr.Levent-MERC\%c4\%b0N-M\%c3\%9cZELER-VE-TOPLUM.pdf

Millî Eğitim Bakanlığı. (2008). İlköğretim 1-8. sinıflar Türkçe, matematik, sosyal bilgiler, hayat bilgisi ile fen ve teknoloji dersi ögretim programlarında müze ile eğitim. Ankara: Talim Terbiye Kurulu Başkanlığı.

Millî Eğitim Bakanlığı. (2019). Müzede eğitim başlıyor. https://www.meb.gov.tr/muzede-egitim-basliyor/haber/18739/tr

Özmen, S. S. (2018). Müze eğitiminin gelişimi. Humanitas, 6(11), 301-324.

Şar, E. ve Sağkol, T. (2013). Eğitim fakültelerinde müze eğitimi dersi gerekliliği üzerine. Hasan Ali Yücel Eğitim Fakültesi Dergisi, 10(2), 83-90.

Tezcan-Akmehmet, K. ve Ödekan, A. (2011). Müze eğitiminin tarihsel gelişimi. İtü Dergisi, 3(1), 47-58.

Timetürk. (2011). Çocuk Dostu Müze Projesi’nde Unicef ile işbirliği -Unicef ile birlikte müze ĕgitimi. https://www.timeturk.com/tr/2011/01/27/cocuk-dostu-muze-projesi-nde-unicef-ile-isbirligi-unicef-ile-birlikte-muze-egi.html

Türk Dil Kurumu. (2020). Türkçe güncel sözlük. https://sozluk.gov.tr/ adresinden edinilmiştir.

Utku, N. (2015). Müzedeki sandık (2. baskı) (A. Aktoptan Erol, İllus.). Bursa: Patikalar Dergisi Yayınları.

Ünal, F. ve Pınar, Y. (2017). Çocuklarla müze deneyimi. İdil, 6(38), 2899- 2917.

Verde, S. (2020). Müze (5. baskı) (P. H. Reynolds, İllus.). (M. Beykan, Çev.). İstanbul: Gün Işığı Kitaplığı. (Orijinal çalışma basım tarihi 2013.)

Yıldırım, A. ve Şimşek, H. (2008). Sosyal bilimlerde nitel araştırma yöntemleri. Ankara: Seçkin Yayıncılık.

Yılmaz, M. (2010). Ĕ̈itimin her kademesine yönelik görsel sanatlar ĕgitiminde uygulamalar. Ankara: Data Yayınları. 